\title{
The Restorative Environment and Salutogenesis: Complementary Concepts Revisited
}

\author{
Eike von Lindern, Freddie Lymeus, and Terry Hartig
}

\section{Introduction}

People deplete adaptive resources in facing the demands of everyday life, and environments differ in the support they afford for renewal of depleted resources. Environments that promote the renewal of adaptive resources, called restorative environments, have attracted attention in diverse disciplines. Both theoretically and practically, work with restorative environments can complement work guided by a stress perspective on adaptation that focuses on demands from the environment and ways of minimising and mitigating them. Work concerning restorative environments thus shares with salutogenesis studies a positive perspective on circumstances that promote health, effective action and well-being.

The two fields also have common roots in the study of stress, and they have emerged and taken form during roughly the same period from the 1970s on. Despite their similarities in perspective and origin, however, the two fields appear to have developed largely in parallel, without systematic exchange. Many researchers interested in restorative environments do refer to salutogenesis in a broad sense and have some familiarity with the literature on salutogenesis. However, those who study salutogenesis in the tradition of Antonovsky would find that little research on restorative environments has empirically addressed theoretical claims concerning, for example, the sense of coherence as a gener-

This chapter is a revision and update of work published in Mittelmark, M.B., Sagy, S., Eriksson, M., Bauer, G., Pelikan, J.M., Lindström, B., \& Espnes, G.A. (eds). (2017). The Handbook of Salutogenesis. Springer, Cham. DOI: https://doi.org/10.1007/978-3-319-04600-6.

E. von Lindern $(\bowtie)$

Dialog N - Research and Communication for People, Environment and Nature, Zurich, Switzerland

e-mail: eike.von.lindern@ dialog-n.ch

F. Lymeus · T. Hartig

Institute for Housing and Urban Research and Department of

Psychology, Uppsala University, Uppsala, Sweden alised resistance resource. Our reading of the literature on salutogenesis suggests to us that this neglect is mutual.

In this chapter, we consider how research on restorative environments can augment research on salutogenesis by calling attention to the dynamics of depletion and renewal of resources needed for the maintenance and promotion of health and well-being, and by showing how the sociophysical environment comes into play in people's ongoing efforts to manage diverse resources. We also consider how research on salutogenesis can augment research on restorative environments by encouraging a broader view of the kinds of resources that can be depleted and the different levels on which they are organised and become available. In this chapter, we thus indicate areas for more systematic, reciprocal exchange between the fields.

In the first of the following sections, we outline the restoration perspective and define key concepts and contexts of research on restorative environments. In the next section, we go on to overview theoretical and empirical research on restorative environments. In the subsequent section, we discuss implications of research on restorative environments for further research and for interventions that bridge the concerns of the two fields. In the final section, we consider some challenges for the future, covering possible reasons why exchange between the fields has been limited and reasons why both fields would benefit from engaging more systematically. Throughout, we provide points of entry into the literature for researchers and practitioners in both fields.

\section{Key Concepts}

In this section, we discuss the restoration perspective and four key concepts: resources, the antecedent condition of resource depletion, the restorative environment and constrained restoration. Throughout our discussion, we consider similarities and dissimilarities in thinking about salutogenesis and restorative environments. 
Environmental psychologists have long understood that the study of restorative environments provides a needed complement to inquiry into stress and coping (Saegert, 1976; Saegert \& Winkel, 1990). More recently, this complementarity has been framed in terms of different perspectives on adaptation to changing environmental circumstances (Hartig, 2001, 2008; Hartig et al., 2008). Each of these perspectives is defined in terms of its basic theoretical and practical premises, summarised in Table 35.1.

The contrast between the stress and coping perspectives resembles the contrast between the pathogenic and salutogenic perspectives outlined by Antonovsky (1979). The impact of stress on health has from the start been a major concern of salutogenesis research. While stress has more traditionally been viewed as a pathogenic factor that engenders susceptibility to illness and ill-being and that should therefore be eliminated or avoided, the salutogenic perspective accepts that stressful demands are omnipresent and that stress is unavoidable and to some degree even desirable in any normal life (Antonovsky, 1979). For research on salutogenesis, the central questions have thus become: How can people stay healthy despite experiencing even extremely stressful circumstances? And what causes health (as opposed to what causes disease)?

For its part, the restoration perspective complements the stress and coping perspectives-and the pathogenic and salutogenic perspectives - by noting that even though a person may have ample protection from environmental demands, as well as ample resources available for use, that person will still need to restore adaptive resources periodically. A person unavoidably depletes some resources while pursuing goals and otherwise going through the activities of daily life, and this may make it difficult to proceed even though other resources may remain available. It is, therefore, necessary to restore depleted resources to continue with mundane activities and to maintain adaptation to the environment.

Table 35.1 Perspectives on human adaptation to the environment

\begin{tabular}{l|l|l|l}
\hline & Stress & Coping & Restoration \\
\hline $\begin{array}{l}\text { Theoretical } \\
\text { premise }\end{array}$ & $\begin{array}{l}\text { Perspective } \\
\text { demands can } \\
\text { undermine } \\
\text { adaptation }\end{array}$ & $\begin{array}{l}\text { Perspective } \\
\text { available } \\
\text { resources } \\
\text { support } \\
\text { adaptation }\end{array}$ & $\begin{array}{l}\text { Perspective } \\
\text { requires periodic } \\
\text { restoration }\end{array}$ \\
\hline $\begin{array}{l}\text { Practical } \\
\text { premise }\end{array}$ & $\begin{array}{l}\text { Interventions } \\
\text { can eliminate } \\
\text { or mitigate } \\
\text { demands }\end{array}$ & $\begin{array}{l}\text { Interventions } \\
\text { can enhance } \\
\text { the availability } \\
\text { of resources }\end{array}$ & $\begin{array}{l}\text { Interventions } \\
\text { can enhance } \\
\text { opportunities for } \\
\text { restoration }\end{array}$ \\
\hline $\begin{array}{l}\text { Relation to } \\
\text { salutogenic } \\
\text { perspective }\end{array}$ & $\begin{array}{l}\text { Contrast: } \\
\text { comparable to } \\
\text { the pathogenic } \\
\text { perspective }\end{array}$ & $\begin{array}{l}\text { Congruent: } \\
\text { subsumes the } \\
\text { salutogenic } \\
\text { perspective }\end{array}$ & $\begin{array}{l}\text { Complement: } \\
\text { calls attention to } \\
\text { issues of } \\
\text { resource } \\
\text { depletion and } \\
\text { renewal }\end{array}$ \\
\hline
\end{tabular}

\section{Resources}

Our outline of perspectives reveals a common concern for adaptive resources, just as it indicates that the study of restorative environments differs from salutogenesis studies in its emphasis on resource depletion, renewal, and, by implication, resource management. Consider the differences between the resources of interest. Salutogenesis research takes interest primarily in individual or societal resources that support people in maintaining or improving their health and well-being despite the presence of stressors. In salutogenesis research, two key health resource concepts have been defined: generalised resistance resources and the sense of coherence.

Generalised resistance resources can be understood as biological, material and psycho-social factors that help people perceive their lives as consistent, structured and understandable or meaningful (Antonovsky, 1987). The sense of coherence is a "global orientation that expresses the extent to which one has a pervasive, enduring though dynamic feeling of confidence that one's internal and external environments are predictable and that there is a high probability that things will work out as well as can reasonably be expected" (Antonovsky, 1979, p. 123). A strong sense of coherence is thought to enable people to manage their lives, even when unpredictable events happen, as with a major illness or the loss of a job. Of particular note, salutogenesis research has emphasised the stability of sense of coherence across situations, with the relative strength of the sense of coherence consistently influencing a person's susceptibility to stress.

In contrast, restorative environments research takes an interest in resources that can vary greatly in their availability over time, including cognitive capabilities such as directing attention, physical capabilities such as mobilising the body for action and social capabilities such as the ability to call on a friend for help. Concomitantly, it also takes an interest in the circumstances that cause the availability of resources to vary across everyday situations, particularly the types of person-environment encounters that deplete resources and those that help people recover adaptive capabilities. Given recognition of the mundane and often predictable depletion of resources, as well as how people regularly use environments for restoration, research in the field also takes an interest in the deliberate management of resources and the acquisition of skills in managing resources (Kaplan, 2001; Lymeus, 2019).

The difference between the two fields in the treatment of resources is significant. The availability of resources referred to in salutogenesis research might show level shifts due to events such as losing one's job or making new friends. Still, changes in resources over a day or week are not the main concern in salutogenesis research (Antonovsky, 1979). 
Rather, Antonovsky assigned little weight to minor fluctuations or momentary deviations from a more global and general sense of coherence, thereby discounting the importance of the kind of changes in resource levels that are of concern in restorative environments research. Research on restorative environments, on the other hand, assumes that these resource dynamics can influence a person's functioning from day to day and accumulate to substantially affect health and well-being in the longer term. These resource dynamics can also play a role in the availability of generalised resistance resources as discussed from a salutogenic perspective. For example, a person's sense of coherence may depend on the adequacy of regular restoration of other resources; a seemingly stable low level of sense of coherence may reflect circumstances of persistent inadequacy of more basic resources needed to meet recurrent adaptive demands.

\section{Antecedent Condition for Restoration}

We have indicated that research on restorative environments assumes that people deplete adaptive resources as they pursue goals and otherwise try to meet the requirements of everyday life. This assumption is logically necessary, as the potential for restoration only exists if some resource has become depleted. A task for research is then to describe how the resource becomes depleted and the consequences of its depletion. Conceivably, this task can be undertaken with any psychosocial resource, including sense of coherence (cf. Hartig, 2004).

Also, as indicated earlier, adaptive resources take different forms. It follows that the antecedent conditions from which people can restore can differ substantially in character, as can the circumstances needed for the renewal of the given resource. Along with the specification of the antecedent condition, the description of the process of restoration is a basic concern of any theory about restorative environments (Hartig, 2004). To date, given the discounting of the dynamic aspects of sense of coherence, theory has not systematically addressed the circumstances under which it becomes transiently depleted or environmental supports for its recovery. When such a theory is developed, it will presumably have features in common with those theories that have been formulated to address the restoration of other resources. We will discuss those theories in the next section. In this section, we consider the concept of restorative environment in general terms.

\section{The Restorative Environment}

Regardless of which resource has become depleted, a precondition for its restoration is that the sociophysical environment will support that process. Environments can support restoration in two general ways. First, a relative absence of perceived social and physical demands (e.g. crowding, noise, reminders of paid work or other obligations) in an environment may permit restoration. Second, certain qualities of the environment can promote restoration.

Defined in a positive sense, then, restorative environments do not only permit restoration but also promote restoration, enabling faster, more complete recovery of depleted resources than environments that are relatively free of demands but which lack positive features. Restorative environments can accordingly be defined as environments that both permit and promote restoration (Hartig, 2004). Given that sense of coherence and other generalised resistance resources of interest from a salutogenic perspective are subject to the kinds of resource dynamics of concern in the study of restorative environments, one could ask just what environmental conditions are needed to support the renewal of those resources; that is, what depleting conditions should be absent, and what restoration-promoting conditions should be present?

\section{Constrained Restoration}

In attending to environmental conditions that promote versus only permit restoration, research on restorative environments has enabled a theoretical distinction between environmental conditions that deplete resources and those that disallow or slow restoration (Collado et al., 2016; Hartig, Catalano, \& Ong, 2007; Hartig, Kylin, \& Johansson, 2007; von Lindern, 2015, 2017; von Lindern et al., 2013). The distinction becomes particularly meaningful when considering the causes of chronic stress. Stress can become chronic when stressor exposures persist, when one is unable to acquire new skills or resources to better cope with those stressors, when one cannot manage to apply the resources at disposal more efficiently, and when one fails to adequately restore needed resources that have been depleted. The concept of constrained restoration recognises that the failure to adequately restore may occur for reasons other than the direct effect of stressor exposures. A person may not be able to restore depleted resources because of prevailing environmental conditions that overlap little with the stressor exposures that deplete resources and which are not themselves perceived as direct sources of stressful demands.

For example, in the initial work on this concept, Hartig, Catalano, and Ong (2007) treated cool summer weather as an environmental condition that people could easily avoid by staying indoors, but which would in turn limit access to outdoor environments of relatively high restorative quality. Looking at monthly data over an 8-year period, they found that dispensation of antidepressants to the Swedish population was higher during relatively cool Julys compared 
to warmer Julys, the period when many workers take the greater part of their annual vacation (see also Hartig \& Catalano, 2013).

Thus, environmental characteristics that constrain restoration need not impose substantial demands on a person's resources, yet they can contribute to chronic stress by impairing the restoration of resources that were depleted earlier. Given that the dynamics of resource depletion are relevant for a discussion of generalised resistance resources as considered from a salutogenic perspective, the possibility of constrained restoration also becomes relevant for salutogenesis research.

\section{Key Cultural, Practice and Research Contexts}

One broad objective for restorative environments research is to inform environmental strategies for supporting restoration. Such strategies may be embedded within a specific therapeutic or rehabilitative intervention, but they are not limited to contexts of therapy or rehabilitation. By focusing on ordinary forms of depletion and renewal of adaptive resources, restorative environments research takes interest in the full range of environments in which people commonly face demands and find opportunities for restoration. These environments incorporate social and cultural characteristics as well as physical ones, and they ordinarily involve the performance of particular activities. By way of illustration here, in the following, we discuss several broad environmental categories that have received substantial attention to date: natural and urban environments, residential environments and healthcare environments.

\section{Natural and Urban Environments}

Embedded as they are within urbanised societies, restorative environment researchers often work with a pragmatic and coarse distinction between urban and natural environments. On the one hand, they are concerned about the harmful consequences of stressful conditions in urban environments in which so many people spend some of their time. On the other hand, they are concerned about the loss to ongoing urbanisation of natural environments that support restoration. Although the restorative values of seemingly untouched wilderness have long been acknowledged in the literature (Knopf, 1987), the natural environments used in studies as relatively restorative comparison conditions are rarely completely natural, in the sense of being untouched by human activity.

Rather, putting aside a strictly objective definition, researchers and practitioners have focused on the restorative value of environments perceived as relatively natural and on opportunities for contact with nature, wherever they might occur, from urban parks to indoor plants (Bringslinmark et al., 2009). It can thus be sufficient that vegetation or some other representation of nature comes into a person's subjective awareness.

Reflecting these definitional issues, researchers often use terms such as "green space," "open space," or simply "nature" to identify the environmental construct of interest. The terminological choices may themselves reflect the background of the given researchers or practitioners, who come from diverse academic and professional disciplines, such as environmental psychology, human geography, interior design, landscape architecture and occupational therapy.

Recent years have seen a reaction against the notion that nature should always be regarded as the more restorative alternative to an urban environment. Some researchers have noted that the environments used in studies-often dominated by streets and sidewalks with busy pedestrian and vehicular traffic-do not well represent the urban environment (Karmanov \& Hamel, 2008), and that many environments in the urban context, such as cafés, are frequently sought out and enjoyed for restoration despite an absence of natural content (Staats et al., 2010).

Theories in the area, reviewed later, do offer explanations for why natural environments might more effectively support restoration than other environments, but they do not deny the possibility of restorative experiences in urban surroundings. Both relatively natural and relatively urban environments may support restorative processes such as psychophysiological stress recovery or attention restoration (details given later) to the degree that they enable experiences with particular components. Some types of environments are more likely to support such experiences, and these environments may be defined as generalised resistance resources from a salutogenic perspective and as such contribute to a sense of coherence.

\section{Residential Environments}

Another common focus for restorative environments research and practice involves the everyday residential context in which people spend so much of their time. The concern for where people live often overlaps with the concern for the relative restorative qualities of natural versus urban environments, as with studies of self-reported health or different causes of mortality in relationship to green or blue (waterrelated) space near the residence (e.g. Astell-Burt et al., 2014; De Vries et al., 2003; Mitchell \& Popham, 2008; White et al., 2013). Such studies commonly assume that nearby green or blue space can over time become positively associated with indices of health through pathways that involve the cumulative effects of repeated episodes of adequate restora- 
tion in the residential environment (Astell-Burt et al., 2014; Hartig et al., 2014). This may show, for example, in prospectively reduced risk of psychiatric disorders (Engemann et al., 2019) and all-cause mortality (Rojas-Rueda et al., 2019).

Not all of the research concerned with restoration in the residential context is, however, concerned with contact with nature in and around the home. Some research has, for example, considered how architectural characteristics of densely built urban residential areas can boost restorative quality (Lindal \& Hartig, 2013; Weber \& Trojan, 2018). Beyond such specific issues, research in the area recognises that people associate their home with personally important activities and find in the residential context many possibilities for satisfying basic psychological and social needs (e.g. Easthope, 2004; Hartig et al., 2003a; Lawrence, 1987; Stokols, 1976).

Many people withdraw into the home after a long day of work or studies, detach from the outside world and engage with people and activities in ways that promote restoration not only of physical and cognitive resources but also of social resources, including resources of potential interest to students of salutogenesis. Studies in different disciplines looking over many different cultural contexts indicate that residence or "home" is commonly associated with feelings of security, control, permanence and continuity, relatedness and refuge from the outside world (e.g. Després, 1991; Somerville, 1997), all of which in one way or another can figure in restorative experiences that might contribute to a strong and stable sense of coherence.

In line with this idea, research on people's self-identified favourite places has offered a window into the use of the residential environment for restoration as subordinate to an overarching process of self-regulation that serves multiple functions, including the maintenance of a coherent representation of reality and a favourable level of self-esteem (Korpela et al., 2001; Korpela et al., 2010; Korpela \& Hartig, 1996). Other recent research acknowledges that the restorative qualities of residential environments may become constrained by environmental conditions such as traffic-related exposures (e.g. von Lindern et al., 2016) and by efforts to cope with work demands by bringing paid work into the home (Ahrentzen, 1989; Hartig, Kylin, \& Johansson, 2007).

\section{Healthcare Environments}

Like the foregoing environmental categories, the final category we will consider here includes diverse contexts constituted of varying combinations of people, activities and physical environmental features. Also, just as the residential and natural categories overlap with each other, so does the healthcare category overlap with each of them. Guided by theories about restorative environments, much of the research in this area has considered how contact with nature can support caregiving in a range of institutional settings, some of which are residential in character.

There are many examples: screens showing nature imagery in waiting rooms for people about to give blood (Ulrich et al., 2003), virtual reality representations of nature used during dental procedures (Tanja-Dijkstra et al., 2014), large landscape scenes presented on curtains around beds where patients laid while undergoing an uncomfortable bronchoscopy procedure (Diette et al., 2003), window views of trees from a hospital room in which patients spent several days recovering from surgery (Ulrich, 1984), window views over the surrounding landscape from the rooms of patients going through rehabilitation programmes several weeks in length (Raanaas et al., 2012), and outdoor garden spaces at assisted living facilities in which elderly people were receiving daily care during the remainder of their lives (Dahlkvist et al., 2016; Ottosson \& Grahn, 2005).

Although the contexts vary widely, and with them the specific issues addressed in the provision of care, a common concern is to help people better cope with pain and stress induced by illness, treatment and the environment in which treatment takes place. The literature tends to affirm the value of contact with nature in these environments, providing positive distractions that help to buffer people against anxiety, pain and stress and promoting more rapid recovery from the stress of treatment they nonetheless experience, whether acutely or over extended periods.

Moreover, work in this area recognises that benefits of restorative amenities in healthcare environments can accrue not only to those who receive care, but also to those who provide it and to the family members and friends who are there to support care recipients (Hartig \& Cooper Marcus, 2006). From a salutogenic perspective, such outcomes can help people maintain their sense of coherence by enhancing the manageability of care, and perhaps, as well, its comprehensibility and the meaning it holds.

\section{Theoretical and Empirical Research}

In the foregoing section, we introduced the restoration perspective and defined key concepts and contexts for research and practice concerned with restorative environments. In this section, we give an overview of theories about restorative environments and additional empirical research. Our coverage here of empirical findings from experimental, epidemiological and clinical studies is only illustrative; the research area has expanded rapidly in recent years, and an exhaustive treatment of the many developments is beyond the scope of this chapter. The overview nonetheless enables us to note points of relevance for the study of salutogenesis. 


\section{Basic Theory and Research on Restorative Processes}

The environmental qualities that permit and promote restoration are the subject of two prominent theories in environmental psychology, namely, psychophysiological stress recovery theory (Ulrich, 1983; Ulrich et al., 1991) and attention restoration theory (Kaplan, 1995; Kaplan \& Kaplan, 1989). These theories grew out of concern for the psychological values of natural environments, and they have guided much of the research in the area so far, which has focused predominantly on the relative restorative value of natural environments. In specifying an antecedent condition from which a person restores, both refer to work done with individual resources under the general environmental stress rubric (Hartig, 2004). In the following, we will outline these two theories, as well as three more recent theoretical proposals that address knowledge gaps with respect to the resources under consideration, restorative processes and the conditions in sociophysical environments that support those processes.

\section{Psychophysiological Stress Recovery Theory}

The psychophysiological stress recovery theory (Ulrich, 1983; Ulrich et al., 1991) focuses on the affective response to particular stimulus patterns and contents in the visual stimulus array. The theory assumes that some visual characteristics support stress reduction and that this has an innate basis. Stress is one manifestation of the operation of an evolved affective system that directs approach and avoidance behaviour.

For example, an acute stress response may be triggered by visual stimuli that are perceived as threatening, such as a looming dark shape. That affective response involves the physiological activation necessary to execute appropriate behaviour, such as fighting or fleeing. Pleasant emotions are considered as another part of the same evolved system: an affective response to visual stimuli that signal an opportunity for relaxation and recovery of depleted adaptive resources. The process of stress recovery is thought to be initiated by positive affective responses that derive from perceiving a scene as mildly to moderately interesting, pleasant and calm.

Restoration will be facilitated if the visual stimulus array has moderate depth, moderate complexity, provides a focal point and contains particular environmental contents. It is believed that the characteristics typical of savannah landscapes (e.g. with regard to the shape and distribution of trees and grassy uniform ground), as well as the presence of water, are especially likely to evoke restorative responses, because these landscapes resemble the primary environments of human evolution, when the given characteristics signalled possibilities relevant for survival.
Following a stressful encounter with circumstances that are perceived as threatening to well-being, a person viewing such a pleasant scene will feel positive affects replacing the negative ones, affirming that well-being is being fostered instead of threatened. The person will concomitantly experience decline in physiological activation to a more moderate level. An innate tendency to respond this way in appropriate situations would hold survival value by enabling faster recovery from acute stress, thus providing protection against chronic stress and ensuring the ability to adapt to changing circumstances in the long term.

Empirical support for this theory has been discerned in the results of experiments in laboratory and field settings by Ulrich (1979), Ulrich et al. (1991) and others (e.g. Hartig et al., 2003b; Parsons et al., 1998). Importantly, very similar theoretical notions that seem to have been developed without awareness of Ulrich's work have also received experimental affirmation. Specifically, Fredrickson and Levenson (1998) tested an "undoing hypothesis" that invokes essentially the same affective mechanism for stress recovery described in 1983 by Ulrich; positive affect evoked by some environmental stimuli blocks negative affect and thoughts and enables more rapid, complete psychophysiological stress recovery. Such studies speak to the plausibility of the theory. Looking across multiple experiments, one meta-analysis has affirmed the beneficial effects of contact with nature in terms of reduced feelings of anger, anxiety, fatigue and sadness; however, they found too few suitable experiments to reliably affirm physiological benefits (Bowler et al., 2010).

\section{Attention Restoration Theory}

Another prominent theory concerned with restorative environments is attention restoration theory (ART) (Kaplan, 1995; Kaplan \& Kaplan, 1989). It construes effective functioning as fundamentally reliant on the cognitive ability to direct attention, that is, to wilfully focus on what is necessary or relevant for fulfilling a specific task (e.g. writing a report) and so to inhibit processing of irrelevant stimuli (e.g. a conversation in the hallway) and inappropriate behaviours (e.g. angry outbursts). The capacity to direct attention is limited in its momentary span, so that high simultaneous demands limit the ability to handle additional demands (Choi et al., 2014; Lavie, 2010).

It is also limited in its temporal scope, so that sustained efforts to direct attention can deplete the resource (Hockey, 1997; Kurzban et al., 2013; Sarter et al., 2006), which brings with it gradually impaired performance and, eventually, fatigue of the self-regulatory capability (e.g. Cohen, 1980; Kaplan \& Berman, 2010). ART assumes that many commonplace tasks and other everyday demands tax the directed attention resource. It follows that having sufficient 
opportunities to restore the capability to direct attention is important for effective functioning, health and well-being.

In contrast to environments that require individuals to direct their attention to function effectively, restorative environments support an effortless mode of operation (Kaplan \& Kaplan, 1989). This means that individuals can attend and act in accordance with their own inclinations by simply letting their attention go to what they find interesting. According to ART, an environment is restorative if it is rich in fascinating features, is perceived as coherently ordered and of substantial scope and is compatible with what the individual wants to do.

Additionally, a restorative environment permits a person to have a sense of psychologically being away, not having to engage with routine mental contents, including those associated with everyday tasks and demands. Taken together, these characteristics allow people to become positively engaged with pleasantly interesting experiences in the moment, with few constraints and interruptions. This, in turn, enables rest of the neurocognitive foundations of directed attention. Regular restoration can thus protect against fatigue and selfregulatory failures that could otherwise have undesirable consequences and it can mitigate stress by bolstering the resources needed to deal with demanding or threatening situations. Kaplan and Kaplan (1989) assert that natural environments, more than most environments, provide such restorative opportunities (see also Kaplan, 1995; Kaplan et al., 1998).

Empirical support for this theory has been discerned in the results of true and quasi-experiments in laboratory and field settings, some of which have concerned single, brief occasions spent in natural versus urban environments (e.g. Berman et al., 2008; Hartig et al., 2003b; Hartig et al., 1991) or different kinds of natural environments (e.g. Gatersleben \& Andrews, 2013; Ratcliffe et al., 2013) and others of which assumed repeated contacts with nature in a residential or therapeutic context (e.g. Kuo \& Sullivan, 2001; Cimprich, 1993; for a selective review, see Kaplan \& Berman, 2010). In their meta-analysis, Bowler et al. (2010) could not reliably affirm attentional benefits of nature experiences on the basis of the results available at that stage in the development of the literature. Subsequent reviews of the experimental literature have described cognitive benefits of nature experience, though not for all measures taken to represent directed attention capacity, thereby raising more specific questions about the character of the cognitive processes at work (Ohly et al., 2016; Stevenson et al., 2018).

\section{Social Aspects of Restorative Experience}

The theoretical contributions just reviewed acknowledge the significance of social aspects of the environment in different ways. Much of the emphasis in their discussions of social aspects is, however, negative. Interactions with others are considered as causes of resource depletion, as when high social density imposes demands on attention, or they are considered with regard to a need for restoration, as when a hard-pressed individual too quickly shows irritation or a lack of attentiveness towards others. More recent work in environmental psychology has, however, begun to more deliberately consider how other people can help to advance the process of restoration.

This positive view of how others figure in restorative experience is treated more extensively in work by Staats and colleagues, who have described how others may enable more restorative experiences, as when one person helps another to feel safe when going into a wild forest area, as well as enhance restorative experiences, as when exploring an environment and discovering its particular features together (e.g. Staats et al., 2010, 2016; Staats \& Hartig, 2004). The significance of social roles and social circumstances that may positively or negatively impact restorative experiences is also apparent in von Lindern's $(2015,2017)$ discussion of how restorative environments research can be informed by behaviour setting theory.

\section{Insights from Behaviour Setting Theory}

Many studies on the association between access to natural environments and human health assume that a key pathway involves repeated restorative experiences over time (for overviews, see, e.g. Abraham et al., 2010; Hartig et al., 2014; Kabisch et al., 2017). Such findings encourage the perception that, from a salutogenic perspective, natural environments can be regarded as generalised resistance resources. It is too simplistic to assume, however, that adding natural elements to any given environment will necessarily promote restoration, health and well-being. It is important to bear in mind that restorative environments research does not focus on particular environments alone, defined only in some objective sense, but on transactions that join a person and an environment. Whether or not the transaction serves restoration depends not only on the given environment, but also on what the person brings to the exchange with the environment, including experiences and awareness of other environments (cf. Hartig, 1993).

In this regard, the constrained restoration concept is particularly relevant. As illustrated in the study of cold summer weather and dispensation of antidepressants (Hartig, Catalano, \& Ong, 2007), mentioned earlier, restorative processes may be constrained not only by directly stressful events but also indirectly by other more subtle aspects of the environment that are not of themselves particularly demanding. In a further application of the constrained restoration concept, von Lindern et al. (2013) found that restoration 
reported to have occurred with forest visits during leisure time was constrained for people who had a profession related to forests. Moreover, their results suggest that this constraint of restoration occurred not because of excess familiarity with forests or a lack of interest in them, but rather because forest professionals found it harder to achieve a sense of psychological distance from their work-related demands. Similar findings have been reported by Collado et al. (2016) for children who worked with their parents on a family farm.

Such findings imply that a challenge for measurement is to capture not only the experience of the environment per se, but also the experience of the given environment in relation to other environments. A promising approach in this regard is to consider how the perception of an environment available for restoration differs from the circumstances in which a need for restoration arises. The behaviour setting theory initially proposed by Barker (1978) provides useful insights on how to discriminate the environments involved. Behaviour setting theory integrates psychological, social and physical aspects of the environment in accounting for behaviour. The theory combines these aspects in synomorphic relations with specific behaviours and social roles (Wicker, 1992), with the combination referred to as a "behaviour setting." For example, an open-plan office setting will have a number of chairs that have a synomorphic relationship to the behaviour of sitting in front of a respective desk, and the positioning and furnishing of desk spaces in the office will reflect on the arrangement of work and the status of different workers in the office hierarchy. In the course of a day, people usually move from one behaviour setting to another and in doing so, they move between different social roles and perform different behaviours as they engage with the different functions of the settings. The behaviour setting approach asserts that every setting has specific characteristics that support or even evoke some behaviours while also discouraging or preventing others (Schoggen, 1989; von Lindern, 2017). Different behaviour settings may, however, have common features, involve the same people, support similar behaviours and in other respects be interdependent. The more interdependence there is between two behaviour settings, the harder it becomes to discriminate them (Schoggen, 1989; von Lindern, 2015, 2017).

This account of behaviour settings and their characteristics encourages consideration of restorative environments as settings with particular social and physical properties that support particular behaviours, and it particularly directs attention to the degree to which behaviour settings meant or expected to support restoration are free from interdependencies with settings where stressful demands usually are experienced. When strong interdependencies with demanding settings are experienced while spending time in a setting ordinarily relied on for restoration, the restoration process is likely to be constrained. Common forms of restoration constraining setting interdependency involve the intrusion of work-related circumstances into the settings that people turn to during their leisure time (cf. Hartig, Kylin, \& Johansson, 2007; von Lindern, 2017). This approach also implies that when a person interacts with completely different objects, has other cognitions and/or meets people who are primarily not associated with behaviour settings in which demands usually are experienced, then the behaviour setting will help more to support restoration of resources depleted in those other settings.

In an initial test of these notions, von Lindern (2015) found that the more that features of demanding settings overlapped with features of settings available for restoration, the less the participants reported feeling psychologically away and so the poorer their restoration. Further research could demonstrate that perceived setting interdependencies account for a large amount of explained variance in the feeling of being psychologically away, as well as in perceived health and well-being (von Lindern, 2017). The results illustrate how an integration of behaviour setting theory into restorative environments research contributes to a deeper understanding of restorative processes and human-environment transactions.

\section{A Theory of Collective Restoration}

All of the work reviewed earlier emphasises the restoration of individual resources. One recent contribution has, however, considered the environmental circumstances that contribute to renewal of shared resources in a collective process (Hartig et al., 2013). With inputs from environmental psychology, time geography and social epidemiology, this theory considers how the social regulation of time affects population health by affecting the ability of different people to converge in desired social constellations in settings that in other ways also promote restoration. It refers to the social resources that people provide to one another as a general determinant of health, and it assumes that the availability of social resources is predicated on relational resources. Constituted of shared experiences, mutual trust, mutual regard and other aspects of the bonds between people, these resources provide a basis for mutually supportive action by the parties to a relationship.

With regard to the antecedent condition, then, the theory assumes that relational resources held among different people can become depleted, and that this can in turn diminish the availability of different forms of social support. Renewal of relational resources and so preservation of the availability of social resources requires that people can enjoy time together free from the demands of paid work and other obligations. 
Multiple mechanisms can then work simultaneously; free time can enable people to restore the capacity to provide support to one another, ease restrictions on the provision of support, remove some demands for support, help to maintain relationships that precondition the provision of support and enable the contagion of positive mood, even among people who do not know one another. When more people can take more time off, there is an increase in the number and variety of the social constellations that can form as well as the number and variety of places that support restoration which are within reach during the time available.

In the initial test of this theory, Hartig et al. (2013) focused on vacation as an example of the social regulation of time for restoration. In contrast to the documentation of health benefits for individuals, research has otherwise not considered the extent to which benefits of vacationing spread among individuals, an ecological effect that could show in population health. The test used data for Sweden, a society with generous annual vacation provisions in which workers can take much of their time off during the summer months. With monthly data for more than 12 years, time-series modelling uncovered negative associations between the number of people on vacation and aggregate dispensation of antidepressants to the Swedish population. The test involved a log-transformed dispensation variable; the decline in dispensation associated with each additional vacationing worker became larger as the number of vacationing workers increased.

As another indication that benefits spread among people, Hartig et al. (2013) found that the association held for dispensation to men and women of retirement age as well as to men and women of working age. In line with other work in social epidemiology, including the work in the salutogenic tradition initiated by Antonovsky (1979), the results call for attention to the social conditions that determine the access that individuals have to significant resources, such as social resources, which affect multiple disease outcomes through multiple mechanisms (see also Link \& Phelan, 1995; Syme, 1967).

\section{Research on Interventions}

The last few decades have seen markedly increased practical and scientific interest in a range of approaches to preventing ill health and promoting personal development emanating from research fields like behavioural medicine, clinical psychology and cognitive neuroscience. Many of these approaches target individuals who experience self-regulatory insufficiencies. It is thought that, through training in relevant skills, these people can enhance their ability to live with the everyday demands that they expect (or are expected) to be able to handle. Such skill-based approaches involve teaching individuals techniques to manage stress symptoms (e.g. relaxation training; cf. Hazlett-Stevens \& Bernstein, 2012), or, in keeping with a salutogenic perspective, help them expand their stress management capabilities (e.g. coping strategies training; cf. Taylor \& Stanton, 2007) and strengthen their central self-regulatory faculties (e.g. cognitive training; cf. Rabipour \& Raz, 2012). Still other approaches, such as mindfulness training, teach widely applicable skills that serve symptom management as well as the enhancement of self-regulatory capacity and other capabilities needed to manage demanding life circumstances (cf. Brown et al., 2007; Tang et al., 2015). However, individual-level training interventions such as mindfulness courses typically require a substantial investment of effort, time and other limited resources in acquiring new skills or enhancing functional capabilities on a neurocognitive level (see e.g. Lutz et al., 2015; Tang \& Posner, 2009). Such investment can be prohibitive for already strained individuals (Lymeus et al., 2017).

Approaches that emphasise the value of training people to better cope with stressful demands commonly neglect the ways in which restorative environments can be used to serve similar goals without imposing heavy demands on already strained individuals. In contrast, a variety of approaches informed by restorative environments theory have considered the therapeutic value of natural settings in healthcare contexts, alone or in combination with a therapeutic regimen (see reviews by Cooper Marcus \& Barnes, 1999; Dijkstra et al., 2006; Stigsdotter et al., 2011).

Examples include rehabilitation gardens as a setting and treatment complement for people who suffered from stressrelated illness (Corazon et al., 2012; Sahlin et al., 2012) and personal gardens in which breast cancer patients engaged in activities within tailored programmes intended to help them better manage the cognitive resources needed to follow their treatment regimens (Cimprich, 1993). A study on a therapeutic horticulture intervention (Gonzalez et al., 2010) found that change in the severity of symptoms of depression during the course of the 12-week programme was mediated by the participants' experiences of fascination and being away, the constructs described in attention restoration theory.

Touch points between restorative environments theory and mindfulness meditation have stimulated work that integrates an environmental intervention with a mindfulnessbased approach to attention regulation and stress management (Lymeus, 2019). Kaplan (2001) indicated that meditation skills and practices might enhance connection with restorative environmental features, which has stimulated the development of engagement tasks that could enhance restoration outcomes in nature visits (Duvall, 2011; Pasanen et al., 2018) and research on how mindfulness practice in nature could, in turn, enhance engagement for environmental issues (Geiger et al., 2020; Nisbet et al., 2019). Kaplan (2001) also suggested 
that meditation practice in a natural environment might facilitate and deepen the meditative state, which has stimulated the development of meditation aids using virtual nature stimuli (Choe et al., 2020; Costa et al., 2019) as well as research employing mindfulness training interventions in gardens and other natural settings (for an early review of this developing field, see Djernis et al. (2019).

Extending and updating Kaplan's (2001) work, Lymeus et al. (2019) describe how theoretical connections and overlap between several key processes involved in restorative nature experience and mindfulness can be harnessed in specific meditation instructions and utilised in a training format. The resulting course, called restoration skills training (ReST), is an approach to mindfulness training adapted to draw on and enhance connection with restorative environmental qualities in a garden setting. Lymeus et al. (2018) showed that ReST training for student participants with stress and concentration problems enhanced their ability to draw attentional restorative benefits during class meetings in a garden setting. Lymeus et al. (2019) further showed that restorative experiences (i.e., fascination and being away) during meditation practice supported the strained participants in completing the ReST course and establishing a regular meditation practice compared with conventional mindfulness training indoors, which had poorer compliance.

While environmental interventions have the advantage of benefiting people with low levels of adaptive resources without imposing further demands, restoration outcomes are frequently considered to be transient so that regular visits are needed to maintain functioning and health over time (e.g. White et al., 2019). Furthermore, access to restorative nature experience is limited for many urban people, in terms of time and space as well as quality (Bratman et al., 2019; Cox et al., 2017; Hartig \& Kahn, 2016). Individual training approaches have the advantage of producing lasting effects that can be learned and applied in diverse situations. Lymeus et al. (2020; also see Lymeus, 2019) showed that careful integration of the two can retain the advantages and overcome the weaknesses of the two approaches, thus producing generalised benefits for psychological functioning while also incurring minimal additional demands on strained individuals. Bringing skill- and nature-based approaches together could offer additional possibilities for understanding and facilitating mindfulness and restorative states and for understanding the ways in which individual-level and environmental resources more generally could interact to produce salutogenic outcomes.

\section{Discussion of Implications}

The theory and research we have presented so far illustrate the complementarity and potential for integration of the salutogenic and restoration perspectives in health promotion. On the one hand, we have shown how research on restorative environments can augment understanding of salutogenesis. We have called attention to the dynamics of the depletion and renewal of resources needed for maintaining and promoting health, and we have explained how sociophysical environments can play a positive role in people's ongoing efforts to manage diverse adaptive resources. On the other hand, we have shown how research on salutogenesis can augment research on restorative environments. The salutogenic perspective opens for a broader view of the kinds of resources that can become depleted and the different levels on which they are organised and become available. In the following two sections, we elaborate on some implications of these observations for salutogenesis research and practice, with a view to advancing the integration of the two research fields.

\section{Implications for Salutogenesis Research}

One important implication of our discussion to this point is that the regular restoration of depleted adaptive resources can contribute to a strong and stable sense of coherence. As considered by Antonovsky (1979), a person's stressors and resources will change over time. For example, during transitional phases, as when leaving the parent's home or becoming a parent, some of the stressors that a person faces may become more intense, new stressors may arise, resources that previously were available may no longer be at the person's disposal and other resources may become accessible. Although this account addresses change in the individual's life situation, the emphasis is on transitions between relatively long-lasting life stages. As we have already noted, the significance of daily fluctuations in stressors and resource availability was discounted by Antonovsky.

In contrast, the restoration perspective calls attention to the significance for adaptation over the long term of regular restoration in the short term. In this complementary research tradition, the degree to which people manage to restore their depleted resources on a daily basis allows resources to be understood as more or less stable when considered over weeks, months or years; however, attention to a finer temporal resolution is required, for example, to distinguish between resources that are persistently low because a person never acquired them versus those that are low because they are seldom adequately restored in the face of persistent demands and coping responses that make poor use of other resources that may be available.

Thus, it is reasonable to ask about the possibility of an antecedent condition of low sense of coherence from which a person can be restored. A person may have a persistently weak sense of coherence for quite different reasons, some of which can be framed in terms of deficits over long periods in 
more basic, renewable resources on which a sense of coherence may depend.

It follows that a weak sense of coherence may stem from a lack of access to socio-physical environments that support adequate restoration. Therefore, another important implication of our presentation here is that environmental conditions and person-environment transactions can be construed as generalised resistance resources as conceived by Antonovsky (1987), in that they serve the regular restoration that presumably contributes to a strong and stable sense of coherence. A reasonable question then is whether certain kinds of sociophysical environments serve particularly well as generalised resistance resources. As in research on restorative environments more generally, the natural environment may warrant particular attention from salutogenesis researchers in this regard. In addition to serving restoration, nature experiences may also serve a sense of coherence by supporting the acquisition of capabilities that enable people to view circumstances as comprehensible, manageable and meaningful. Related possibilities have received particular attention from scholars of wildland recreation (cf. Brooks \& Williams, 2012; Knopf, 1987).

Similarly, as noted earlier, an extensive body of research has described meanings attached to the "home," such as feelings of security, control and refuge from the outside world (e.g. Després, 1991; Somerville, 1997), that can figure in restorative experiences and so in a strong and stable sense of coherence. Also, other sociophysical environments such as work places or educational settings can help people maintain their sense of coherence during difficult times by enhancing manageability, comprehensibility and meaning; those discussions can be approached with a view to their recognition of restorative functions of person-environment transactions.

Appreciation of the relational character of restorative environments can also be used to advance understanding of how they serve as generalised resistance resources. In this regard, future research can attend to the interdependencies between behaviour settings that may serve to constrain restorative processes and so undermine a sense of coherence (cf. von Lindern, 2015, 2017; von Lindern et al., 2013). Further, only little research on restorative environments concerns special populations such as people with autism spectrum disorder (ASD). ASD is considered among the fastest growing developmental disorders (Li et al., 2019), and people with ASD are especially susceptible to sensory stimuli or overload in the social and physical environment. Li et al. (2019) point out that principles for inclusive and integrative designs could benefit from behaviour setting theory insofar as they could be joined and applied to public parks and natural environments, an approach which has the potential to provide a generalised resistance resource for people with ASD or related conditions.

A related issue has to do with the social regulation of time for restoration, which remains an understudied aspect of restorative environments. Work on this topic will require further integration of knowledge of the mechanisms of individual and collective restoration with knowledge of the ways in which social conditions determine people's spatial-temporal access to opportunities for restoration (Hartig et al., 2013).

As it stands, individual-level research has done little to address the implications that one person's restoration holds for the health of other individuals, their families and other collectives to which they belong. In geographically dispersed, 24-h economies, many people find it difficult to regularly spend time together, and this may diminish the relational resources they hold in common as well as their possibilities for providing support to one another (Strazdins et al., 2006). While the use of communication technologies could in some ways improve access to relational resources, it can also be an additional source of stress (e.g. Lee et al., 2016).

Under such circumstances, some people may prioritise the renewal of relational resources and provision of support to others over their personal restoration needs during time available for restoration. Such trade-offs need further study, as do the broader, collective implications of inequalities in the distribution of time and resources for restoration and access to restorative environments (cf. Hartig et al., 2013; Strazdins et al., 2011).

\section{Implications for Salutogenesis Practice}

An important practical implication of our discussion to this point is that empowering people to make use of environments for restoration fits with a salutogenic orientation to maintain the generalised resistance resources that enable a strong and stable sense of coherence. Practitioners who work with salutogenesis and those who work in the restorative environments field can consider the distinct yet intertwined roles of dynamic resources and relatively stable ones, respectively, for the health and well-being of individuals and general populations. This multi-level perspective may serve as a more complete theoretical foundation for work to strengthen people's sense of coherence and their health.

Efforts to integrate skill-based and environment-based approaches to restorative experience can also provide a source of inspiration for salutogenic interventions that help individuals develop skills that can serve as widely applicable resistance resources. Some of those skills may involve enhancing restorative experience in sociophysical environments that ordinarily would be perceived as lacking in restorative quality, for example, through the use of meditation techniques (Lymeus, 2008, 2019).

Other skills may target behaviour setting interdependencies and involve the disciplined application of techniques such as turning off a mobile phone, closing down e-mail and removing objects associated with stressful demands from 
behaviour settings used for restoration. By applying such techniques, the behaviour setting used for restoration should become a more powerful generalised resistance resource, contributing more to restorative outcomes and thus to a strong and stable sense of coherence.

Results from restorative environments research suggest that salutogenesis research can also frame the protection of natural environments as a positive practical health concern, complementing the traditional pathogenic concerns for preventing the directly harmful effects of pollution and other aspects of environmental degradation (cf. Hartig et al., 2001). A growing body of evidence affirms that members of urbanised societies generally benefit in terms of health and wellbeing from accessing relatively natural environments. Thus, protecting nature and providing access to potential restorative environments can be understood as ensuring access to generalised resistance resources, which, in turn, promote a stronger sense of coherence.

A final form of practical work to mention here involves approaches to addressing inequalities in the distribution of time for restoration and access to restorative contexts (cf. Phelan et al., 2010; Richards, 1999; Rudd, 2019; Strazdins et al., 2011). Policy interventions, for example, might promote collective benefits at different temporal and social scales. For example, recent initiatives in the United States have sought to bring about national legislation that would enable a large proportion of the population to take vacation at about the same time during the summer months, along the lines of legislation currently in place in many other countries (for background, see Ray et al., 2013).

\section{Challenges for the Future}

The restorative environments and salutogenesis fields share some basic ideas and goals, and they complement each other in important respects, theoretically and practically. Both also have their own standing, however, and this entails several challenges. Some of these challenges have already been indicated, as with reconciliation of differences in terminology and foundational literature that reflect on the different disciplinary backgrounds of researchers in the two fields. How resources and resource dynamics should be conceived and weighted appear to us to be particularly significant in this regard.

Other challenges have remained unmentioned thus far. One such challenge is that those working in the two fields may have incompatible practical goals. For example, conserving nature and protecting natural environments are important motives for many working in the restorative environments field, but the protection of nature may disallow activities that could be seen by some as valuable for promoting a sense of coherence, such as the creation of new housing for a growing community. On the whole, however, looking at the integration of the two fields, we see a far greater potential for benefit than for conflict in terms of individual and public health and societal sustainability.

\section{References}

Abraham, A., Sommerhalder, K., \& Abel, T. (2010). Landscape and wellbeing: A scoping study on the health-promoting impact of outdoor environments. International Journal of Public Health, 55, 59-69. https://doi.org/10.1007/s00038-009-0069-z

Ahrentzen, S. (1989). A place of peace, prospect, and ... a P.C.: The home as office. Journal of Architectural and Planning Research, 6, 271-288.

Antonovsky, A. (1979). Health, stress, and coping. Jossey-Bass.

Antonovsky, A. (1987). Unraveling the mystery of health: How people manage stress and stay well. Jossey-Bass.

Astell-Burt, T., Mitchell, R., \& Hartig, T. (2014). The association between green space and mental health varies across the lifecourse: A longitudinal study. Journal of Epidemiology and Community Health, 68, 578-583. https://doi.org/10.1136/jech-2013-203767

Barker, R. G. (1978). Habitats, environments, and human behaviour: Studies in ecological psychology and eco-behavioral science from the Midwest Psychological Field Station, 1947-1972. Jossey-Bass.

Berman, M. G., Jonides, J., \& Kaplan, S. (2008). The cognitive benefits of interacting with nature. Psychological Science, 19, 1207-1212.

Bowler, D. E., Buyung-Ali, L. M., Knight, T. M., \& Pullin, A. S. (2010). A systematic review of evidence for the added benefits to health of exposure to natural environments. BMC Public Health, 10(1), 456. https://doi.org/10.1186/1471-2458-10-456

Bratman, G. N., Anderson, C. B., Berman, M. G., Cochran, B., de Vries, S., Flanders, J., Folke, C., Frumkin, H., Gross, J. J., Hartig, T., Kahn, P. H., Kuo, M., Lawler, J. J., Levin, P. S., Lindahl, T., Meyer-Lindenberg, A., Mitchell, R., Ouyang, Z., Roe, J., ... Daily, G. C. (2019). Nature and mental health: An ecosystem service perspective. Science Advances, 5(7), eaax0903.

Bringslinmark, T., Hartig, T., \& Patil, G. G. (2009). The psychological benefits of indoor plants: A critical review of the experimental literature. Journal of Environmental Psychology, 29, 422-433.

Brooks, J. J., \& Williams, D. R. (2012) Continued wilderness participation: Experience and identity as long-term relational phenomena. In D. N. Cole (comp.), Wilderness visitor experiences: Progress in research and management (proc. RMRS-P-66). Fort Collins: U.S. Department of Agriculture, Forest Service, Rocky Mountain Research Station.

Brown, K. W., Ryan, R. M., \& Creswell, J. D. (2007). Mindfulness: Theoretical foundations and evidence for its salutary effects. Psychological Inquiry, 18(4), 211-237.

Choe, E. Y., Jorgensen, A., \& Sheffield, D. (2020). Simulated natural environments bolster the effectiveness of a mindfulness programme: A comparison with a relaxation-based intervention. Journal of Environmental Psychology, 67, 101382.

Choi, H. H., van Merriënboer, J. J. G., \& Paas, F. (2014). Effects of the physical environment on cognitive load and learning: Towards a new model of cognitive load. Educational Psychology Review, 26(2), 225-244.

Cimprich, B. (1993). Development of an intervention to restore attention in cancer patients. Cancer Nursing, 16(2), 83-92.

Cohen, S. (1980). Aftereffects of stress on human performance and social behavior: A review of research and theory. Psychological Bulletin, 88, 82-108.

Collado, S., Staats, H., \& Sorrel, M. A. (2016). Helping out on the land: Effects of children's role in agriculture on reported psychological restoration. Journal of Environmental Psychology, 45, 201-209. 
Cooper Marcus, C., \& Barnes, M. (1999). Healing gardens: Therapeutic benefits and design recommendations. Wiley.

Corazon, S. S., Stigsdotter, U. K., Moeller, M. S., \& Rasmussen, S. M. (2012). Nature as therapist: Integrating permaculture with mindfulness- and acceptance-based therapy in the Danish Healing Forest Garden Nacadia. European Journal of Psychotherapy \& Counselling, 14(4), 335-347.

Costa, M. R., Bergen-Cico, D., Grant, T., Herrero, R., Navarro, J., Razza, R., \& Wang, Q. (2019). Nature inspired scenes for guided mindfulness training: Presence, perceived restorativeness and meditation depth. In D. D. Schmorrow \& C. M. Fidopiastis (Eds.), Augmented cognition (pp. 517-532). Springer International Publishing.

Cox, D. T., Hudson, H. L., Shanahan, D. F., Fuller, R. A., \& Gaston, K. J. (2017). The rarity of direct experiences of nature in an urban population. Landscape and Urban Planning, 160, 79-84.

Dahlkvist, D., Hartig, T., Nilsson, A., Högberg, H., Skovdahl, K., \& Engström, M. (2016). Garden greenery and the health of older people in residential care facilities: A multi-level cross-sectional study. Journal of Advanced Nursing. https://doi.org/10.1111/jan.12968

De Vries, S., Verheij, R. A., Groenewegen, P. P., \& Spreeuwenberg, P. (2003). Natural environments-healthy environments? An exploratory analysis of the relationship between greenspace and health. Environment and Planning A, 35(10), 1717-1732.

Després, C. (1991). The meaning of home: Literature review and directions for future research and theoretical development. Journal of Architectural and Planning Research, 8, 96-115.

Diette, G. B., Lechtzin, N., Haponik, E., Devrotes, A., \& Rubin, H. R. (2003). Distraction therapy with nature sights and sounds reduces pain during flexible bronchoscopy: A complementary approach to routine analgesia. Chest, 123, 941-948.

Dijkstra, K., Pieterse, M., \& Pruyn, A. (2006). Physical environmental stimuli that turn healthcare facilities into healing environments through psychologically mediated effects: Systematic review. Journal of Advanced Nursing, 56, 166-181.

Djernis, D., Lerstrup, I., Poulsen, D., Stigsdotter, U. K., Dahlgaard, J., \& O'Toole, M. (2019). A systematic review and meta-analysis of nature-based mindfulness: Effects of moving mindfulness training into an outdoor natural setting. International Journal of Environmental Research and Public Health, 16(17), 3202.

Duvall, J. (2011). Enhancing the benefits of outdoor walking with cognitive engagement strategies. Journal of Environmental Psychology, 31(1), 27-35.

Easthope, H. (2004). A place called home. Housing, Theory and Society, 21, 128-138.

Engemann, K., Pedersen, C. B., Arge, L., Tsirogiannis, C., Mortsensen, P. B., \& Svenning, J. C. (2019). Residential green space in childhood is associated with lower risk of psychiatric disorders from adolescence into adulthood. PNAS, 116, 5188-5193.

Fredrickson, B., \& Levenson, R. W. (1998). Positive emotions speed recovery from the cardiovascular sequelae of negative emotions. Cognition \& Emotion, 12(2), 191-220.

Gatersleben, B., \& Andrews, M. (2013). When walking in nature is not restorative-The role of prospect and refuge. Health \& Place, 20, 91-101.

Geiger, S. M., Fischer, D., Schrader, U., \& Grossman, P. (2020). Meditating for the planet: Effects of a mindfulness-based intervention on sustainable consumption behaviors. Environment and Behavior, 52, 1012-1042.

Gonzalez, M. T., Hartig, T., Patil, G. G., Martinsen, E. W., \& Kirkevold, M. (2010). Therapeutic horticulture in clinical depression: A prospective study of active components. Journal of Advanced Nursing, 66(9), 2002-2013

Hartig, T. (1993). Nature experience in transactional perspective. Landscape and Urban Planning, 25, 17-36.

Hartig, T. (2001). Guest editor's introduction [special issue on restorative environments]. Environment and Behavior, 33, 475-479.
Hartig, T. (2004). Restorative environments. In C. Spielberger (Ed.), Encyclopedia of applied psychology (pp. 273-279). Academic.

Hartig, T. (2008). Green space, psychological restoration, and health inequality. Lancet, 372, 1614-1615.

Hartig, T., Bringslimark, T., \& Patil, G. G. (2008). Restorative environmental design: What, when, where, and for whom? In S. R. Kellert, J. Heerwagen, \& M. Mador (Eds.), Bringing buildings to life: The theory and practice of biophilic building design (pp. 133-151). Wiley.

Hartig, T., Catalano, R., Ong, M., \& Syme, S. L. (2013). Vacation, collective restoration, and mental health in a population. Society and Mental Health, 3(3), 221-236. https://doi.org/10.1177/2156869313497718

Hartig, T., Catalano, R., \& Ong, M. (2007). Cold summer weather, constrained restoration, and the use of anti-depressants in Sweden. Journal of Environmental Psychology, 27, 107-116.

Hartig, T., \& Catalano, R. (2013). Cold summer weather, constrained restoration, and very low birthweight in Sweden. Health \& Place, $22,68-74$.

Hartig, T., \& Cooper Marcus, C. (2006). Healing gardens: Places for nature in health care. Lancet, 368, S36-S37.

Hartig, T., Evans, G. W., Jamner, L. D., Davis, D. S., \& Gärling, T. (2003b). Tracking restoration in natural and urban field settings. Journal of Environmental Psychology, 23(2), 109-123.

Hartig, T., Johansson, G., \& Kylin, C. (2003a). Residence in the social ecology of stress and restoration. Journal of Social Issues, 59(3), 611-636. https://doi.org/10.1111/1540-4560.00080

Hartig, T., \& Kahn, P. H. (2016). Living in cities, naturally. Science, 352(6288), 938-940.

Hartig, T., Kaiser, F. G., \& Bowler, P. A. (2001). Psychological restoration in nature as a positive motivation for ecological behavior. Environment and Behavior, 33, 590-607.

Hartig, T., Kylin, C., \& Johansson, G. (2007). The telework tradeoff: Stress mitigation vs. constrained restoration. Applied Psychology: An International Review, 56(2), 231-253. https://doi. org/10.1111/j.1464-0597.2006.00252.x

Hartig, T., Mang, M., \& Evans, G. W. (1991). Restorative effects of natural environment experiences. Environment and Behavior, 23, 3-26.

Hartig, T., Mitchell, R., De Vries, S., \& Frumkin, H. (2014). Nature and health. Annual Review of Public Health, 35, 207-228.

Hazlett-Stevens, H., \& Bernstein, D. A. (2012). Relaxation. In W. T. O'Donohue \& J. E. Fisher (Eds.), Cognitive behavior therapy: Core principles for practice. Wiley.

Hockey, G. R. J. (1997). Compensatory control in the regulation of human performance under stress and high workload: A cognitiveenergetical framework. Biological Psychology, 45(1), 73-93.

Kabisch, N., van den Bosch, M., \& Lafortezza, R. (2017). The health benefits of nature-based solutions to urbanization challenges for children and the elderly: A systematic review. Environmental Research, 159, 362-373.

Kaplan, S. (1995). The restorative benefits of nature: Toward an integrative framework. Journal of Environmental Psychology, 15(3), 169-182. https://doi.org/10.1016/0272-4944(95)90001-2

Kaplan, S. (2001). Meditation, restoration, and the management of mental fatigue. Environment and Behavior, 33(4), 480-506.

Kaplan, S., \& Berman, M. G. (2010). Directed attention as a common resource for executive functioning and self-regulation. Perspectives on Psychological Science, 5(1), 43-57.

Kaplan, R., \& Kaplan, S. (1989). The experience of nature: A psychological perspective. Cambridge University Press.

Kaplan, R., Kaplan, S., \& Ryan, R. L. (1998). With people in mind: Design and management of everyday nature. Island press.

Karmanov, D., \& Hamel, R. (2008). Assessing the restorative potential of contemporary urban environment(s): Beyond the nature versus urban dichotomy. Landscape \& Urban Planning, 86, 115-125.

Knopf, R. C. (1987). Human behavior, cognition, and affect in the natural environment. In I. Altman \& D. Stokols (Eds.), Handbook of environmental psychology (Vol. 1, pp. 783-825). Wiley. 
Korpela, K., \& Hartig, T. (1996). Restorative qualities of favorite places. Journal of Environmental Psychology, 16(3), 221-233.

Korpela, K. M., Hartig, T., Kaiser, F. G., \& Fuhrer, U. (2001). Restorative experience and self-regulation in favorite places. Environment and Behavior, 33(4), 572-589.

Korpela, K. M., Ylén, M., Tyrväinen, L., \& Silvennoinen, H. (2010). Favorite green, waterside and urban environments, restorative experiences and perceived health in Finland. Health Promotion International, 25, 200-209.

Kuo, F. E., \& Sullivan, W. C. (2001). Environment and crime in the inner city: Does vegetation reduce crime? Environment and Behavior, 33(3), 343-367.

Kurzban, R., Duckworth, A., Kable, J. W., \& Myers, J. (2013). An opportunity cost model of subjective effort and task performance. Behavioral and Brain Sciences, 36(6), 661-679.

Lavie, N. (2010). Attention, distraction, and cognitive control under load. Current Directions in Psychological Science, 19(3), 143-148.

Lawrence, R. J. (1987). Housing, dwellings, and homes. Wiley.

Lee, A. R., Son, S.-M., \& Kim, K. K. (2016). Information and communication technology overload and social networking service fatigue: A stress perspective. Computers in Human Behavior, 55, 51-61.

Li, D., Larsen, L., Yang, Y., Wang, L., Zhai, Y., \& Sullivan, W. C. (2019). Exposure to nature for children with autism spectrum disorder: Benefits, caveats, and barriers. Health \& Place, 55, 71-79.

Lindal, P. J., \& Hartig, T. (2013). Architectural variation, building height, and the restorative quality of urban residential streetscapes. Journal of Environmental Psychology, 33, 26-36.

Link, B. G., \& Phelan, J. (1995). Social conditions as fundamental causes of disease. Journal of Health and Social Behavior, 35(extra issue), 80-94.

Lutz, A., Jha, A. P., Dunne, J. D., \& Saron, C. D. (2015). Investigating the phenomenological matrix of mindfulness-related practices from a neurocognitive perspective. American Psychologist, 70(7), 632-658.

Lymeus, F. (2008). Attention as an outcome and a predictor of mindfulness practice: Attentional restoration and capacity in beginning practitioners (Master's thesis). Uppsala, Sweden: Department of Psychology, Uppsala University.

Lymeus, F. (2019). Mindfulness training supported by a restorative natural setting: Integrating individual and environmental approaches to the management of adaptive resources. Acta Universitatis Upsaliensis.

Lymeus, F., Ahrling, M., Apelman, J., de Mander Florin, C., Nilsson, C., Vincenti, J., Zetterberg, A., Lindberg, P., \& Hartig, T. (2020). Mindfulness-based restoration skills training $(\operatorname{ReST})$ in a natural setting compared to conventional mindfulness training: Psychological functioning after a five-week course. Frontiers in Psychology (Environmental Psychology Section), 11, 1560.

Lymeus, F., Lindberg, P., \& Hartig, T. (2018). Building mindfulness bottom-up: Meditation in natural settings supports open monitoring and attention restoration. Consciousness and Cognition, 59, 40-56.

Lymeus, F., Lindberg, P., \& Hartig, T. (2019). A natural meditation setting improves compliance with mindfulness training. Journal of Environmental Psychology, 64, 98-106.

Lymeus, F., Lundgren, T., \& Hartig, T. (2017). Attentional effort of beginning mindfulness training is offset with practice directed toward images of natural scenery. Environment and Behavior, 49(5), 536-559.

Mitchell, R., \& Popham, F. (2008). Effect of exposure to natural environment on health inequalities: An observational population study. The Lancet, 372(9650), 1655-1660.

Nisbet, E. K., Zelenski, J. M., \& Grandpierre, Z. (2019). Mindfulness in nature enhances connectedness and mood. Ecopsychology, 11(2), $81-91$.

Ohly, H., White, M. P., Wheeler, B. W., Bethel, A., Ukoumunne, O. C., Nikolaou, V., \& Garside, R. (2016). Attention restoration theory: A systematic review of the attention restoration potential of exposure to natural environments. Journal of Toxicology and Environmental Health, Part B Critical Reviews, 19, 305-343.

Ottosson, J., \& Grahn, P. (2005). A comparison of leisure time spent in a garden with leisure time spent indoors on measures of restoration in residents in geriatric care. Landscape Research, 30(1), 23-55.

Parsons, R., Tassinary, L. G., Ulrich, R. S., Hebl, M. R., \& GrossmanAlexander, M. (1998). The view from the road: Implications for stress recovery and immunization. Journal of Environmental Psychology, 18(2), 113-140. https://doi.org/10.1006/jevp.1998.0086

Pasanen, T. P., Johnson, K. A., Lee, K. E., \& Korpela, K. M. (2018). Can nature walks with psychological tasks improve mood, self-reported restoration, and sustained attention? Results from two experimental field studies. Frontiers in Psychology, 9, 2057.

Phelan, J. C., Link, B. G., \& Tehranifar, P. (2010). Social conditions as fundamental causes of health inequalities: Theory, evidence, and policy implications. Journal of Health and Social Behavior, 51(1 supplement), S28-S40.

Raanaas, R. K., Patil, G. G., \& Hartig, T. (2012). Health benefits of a view of nature through the window: A quasi-experimental study of patients in a residential rehabilitation center. Clinical Rehabilitation, 26(1), 21-32.

Rabipour, S., \& Raz, A. (2012). Training the brain: Fact and fad in cognitive and behavioral remediation. Brain and Cognition, 79(2), 159-179.

Ratcliffe, E., Gatersleben, B., \& Sowden, P. T. (2013). Bird sounds and their contributions to perceived attention restoration and stress recovery. Journal of Environmental Psychology, 36, 221-228.

Ray, R., Sanes, M., \& Schmitt, J. (2013). No-vacation nation revisited. Center for Economic and Policy Research.

Richards, G. (1999). Vacations and the quality of life: Patterns and structures. Journal of Business Research, 44, 189-198.

Rojas-Rueda, D., Nieuwenhuijsen, M., Gascon, M., Perez-Leon, D., \& Mudu, P. (2019). Green spaces and mortality: A systematic review and meta-analysis of cohort studies. Lancet Planetary Health, 3, 469-477.

Rudd, M. (2019). Feeling short on time: Trends, consequences, and possible remedies. Current Opinion in Psychology, 26, 5-10.

Saegert, S. (1976). Stress-inducing and reducing qualities of environments. In H. M. Proshansky, W. H. Ittelson, \& L. Rivlin (Eds.), Environmental psychology (pp. 218-223). Holt, Rinehart, Winston.

Saegert, S., \& Winkel, G. (1990). Environmental psychology. Annual Review of Psychology, 41, 441-477.

Sahlin, E., Matuszczyk, J. V., Ahlborg, G., \& Grahn, P. (2012). How do participants in nature-based therapy experience and evaluate their rehabilitation? Journal of Therapeutic Horticulture, 22(1), 8-22.

Sarter, M., Gehring, W. J., \& Kozak, R. (2006). More attention must be paid: The neurobiology of attentional effort. Brain Research Reviews, 51(2), 145-160.

Schoggen, P. (1989). Behavior settings: A revision and extension of Roger G. Barker's ecological psychology. Stanford University Press.

Somerville, P. (1997). The social construction of home. Journal of Architectural and Planning Research, 14(3), 226-245.

Staats, H., \& Hartig, T. (2004). Alone or with a friend: A social context for psychological restoration and environmental preferences. Journal of Environmental Psychology, 24(2), 199-211. https://doi. org/10.1016/j.jenvp.2003.12.005

Staats, H., Jahncke, H., Herzog, T. R., \& Hartig, T. (2016). Urban options for psychological restoration: Common strategies in everyday situations. PLoS One, 11(1), e0146213. https://doi.org/10.1371/ journal.pone. 0146213

Staats, H., Van Gemerden, E., \& Hartig, T. (2010). Preference for restorative situations: Interactive effects of attentional state, activity-inenvironment, and social context. Leisure Sciences, 32(5), 401-417.

Stevenson, M. P., Schilhab, T., \& Bentsen, P. (2018). Attention restoration theory II: A systematic review to clarify attention processes 
affected by exposure to natural environments. Journal of Toxicology and Environmental Health, Part B, Critical Reviews, 21, 227-268.

Stigsdotter, U. K., Palsdottir, A. M., Burls, A., Chermaz, A., Ferrini, F., \& Grahn, P. (2011). Nature-based therapeutic interventions. In K. Nilsson, M. Sangster, C. Gallis, T. Hartig, S. De Vries, K. Seeland, \& J. Schipperijn (Eds.), Forests, trees and human health (pp. 309-342). Springer.

Stokols, D. (1976). The experience of crowding in primary and secondary environments. Environment and Behavior, 8, 49-86.

Strazdins, L., Clements, M. S., Korda, R. J., Broom, D. H., \& D’Souza, R. M. (2006). Unsociable work? Nonstandard work-schedules, family relationships, and children's well-being. Journal of Marriage and the Family, 68, 394-410.

Strazdins, L., Griffin, A. L., Broom, D. H., Banwell, C., Korda, R. J., Dixon, J., et al. (2011). Time scarcity: Another health inequality? Environment \& Planning A, 43, 545-559.

Syme, S. L. (1967). Social stress and cardiovascular disease. Implications and future prospects. The Milbank Memorial Fund Quarterly, 45(2, Supplement), 175-180.

Tanja-Dijkstra, K. T., Pahl, S., White, M. P., Andrade, J., Qian, C., Bruce, M., May, J., \& Moles, D. R. (2014). Improving dental experiences by using virtual reality distraction: A simulation study. PLoS One, 9, e91276.

Tang, Y.-Y., Holzel, B. K., \& Posner, M. I. (2015). The neuroscience of mindfulness meditation. Nature Reviews. Neuroscience, 16(4), 213-225.

Tang, Y.-Y., \& Posner, M. I. (2009). Attention training and attention state training. Trends in Cognitive Sciences, 13(5), 222-227.

Taylor, S. E., \& Stanton, A. L. (2007). Coping resources, coping processes, and mental health. Annual Review of Clinical Psychology, 3, 377-401.

Ulrich, R. S. (1979). Visual landscapes and psychological well-being. Landscape Research, 4(1), 17-23.

Ulrich, R. S. (1983). Aesthetic and affective response to natural environment. In I. Altman \& J. F. Wohlwill (Eds.), Behavior and the natural environment (pp. 85-125). Springer. Retrieved from http:// link.springer.com/chapter/10.1007/978-1-4613-3539-9 4.
Ulrich, R. (1984). View through a window may influence recovery. Science, 224(4647), 224-225. https://doi.org/10.1126/ science. 6143402

Ulrich, R. S., Simons, R. F., Losito, B. D., Fiorito, E., Miles, M. A., \& Zelson, M. (1991). Stress recovery during exposure to natural and urban environments. Journal of Environmental Psychology, 11(3), 201-230. https://doi.org/10.1016/S0272-4944(05)80184-7

Ulrich, R. S., Simons, R. F., \& Miles, M. (2003). Effects of environmental simulations and television on blood donor stress. Journal of Architectural and Planning Research, 20(1), 38-47.

von Lindern, E. (2017). Perceived interdependencies between settings as constraints for self-reported restoration. Journal of Environmental Psychology, 49, 8-17. https://doi.org/10.1016/j.jenvp.2016.11.004

von Lindern, E. (2015). Setting-dependent constraints on restoration while visiting a wilderness park. Journal of Outdoor Recreation and Tourism, 10, 29-37. https://doi.org/10.1016/j.jort.2015.06.001

von Lindern, E., Bauer, N., Frick, J., Hunziker, M., \& Hartig, T. (2013). Occupational engagement as a constraint on restoration during leisure time in forest settings. Landscape and Urban Planning, 118, 90-97. https://doi.org/10.1016/j.landurbplan.2013.03.001

von Lindern, E., Hartig, T., \& Lercher, P. (2016). Traffic-related exposures, constrained restoration, and health in the residential context. Health \& Place, 39, 92-100.

Weber, A. M., \& Trojan, J. (2018). The restorative value of the urban environment: A systematic review of the existing literature. Environmental Health Insights, 12, 1178630218812805.

White, M. P., Alcock, I., Grellier, J., Wheeler, B. W., Hartig, T., Warber, S. L., Bone, A., Depledge, M. H., \& Fleming, L. E. (2019). Spending at least 120 minutes a week in nature is associated with good health and wellbeing. Scientific Reports, 9(1), 7730.

White, M. P., Alcock, I., Wheeler, B. W., \& Depledge, M. H. (2013). Coastal proximity, health and well-being: Results from a longitudinal panel survey. Health \& Place, 23, 97-103.

Wicker, A. W. (1992). Making sense of the environment. In W. B. Walsh, K. H. Clark, \& R. H. Price (Eds.), Person-environment psychology: Models and perspectives (pp. 158-191). Lawrence Erlbaum.

Open Access This chapter is licensed under the terms of the Creative Commons Attribution 4.0 International License (http://creativecommons. org/licenses/by/4.0/), which permits use, sharing, adaptation, distribution and reproduction in any medium or format, as long as you give appropriate credit to the original author(s) and the source, provide a link to the Creative Commons license and indicate if changes were made.

The images or other third party material in this chapter are included in the chapter's Creative Commons license, unless indicated otherwise in a credit line to the material. If material is not included in the chapter's Creative Commons license and your intended use is not permitted by statutory regulation or exceeds the permitted use, you will need to obtain permission directly from the copyright holder. 